\title{
Acylhydrazide and Isatin Schiff Bases as Alternate UV-Laser Desorption Ionization (LDI) Matrices for Low Molecular Weight (LMW) Peptides Analysis
}

\author{
Syed Ghulam Musharraf ${ }^{1,2 *}$, Aisha Bibi ${ }^{2}$, Najia Shahid ${ }^{2}$, Muhammad Najam-ul-Haq ${ }^{3}$, Momin Khan², \\ Muhammad Taha ${ }^{2}$, Uzma Rasool Mughal ${ }^{2}$, Khalid Mohammed Khan ${ }^{2}$ \\ ${ }^{1}$ Panjwani Center for Molecular Medicine and Drug Research, International Center for Chemical and Biological Sciences, \\ University of Karachi, Karachi, Pakistan \\ ${ }^{2}$ Hussain Ebrahim Jamal Research Institute of Chemistry, International Center for Chemical and Biological Sciences, \\ University of Karachi, Karachi, Pakistan \\ ${ }^{3}$ Department of Chemistry, Bahauddin Zakariya University, Multan, Pakistan \\ Email: ${ }^{*}$ musharraf1977@yahoo.com
}

Received September 27, 2012; revised October 30, 2012; accepted November 12, 2012

\begin{abstract}
Matrix-assisted laser desorption/ionization (MALDI) is a preferred and widely used mass spectrometric technique for the analysis of macromolecules. Limited UV-LDI matrices are available for the analysis of biomolecules due to the restricted structural features to serve in the laser desorption/ionization mechanism with a problem of background signals appearing in the low mass region. This paper describes the application of Schiff base derivatives of acylhydrazide and isatin as alternate UV-LDI matrices for the analysis of peptides with significantly low background signals. Thirty one compounds have been successfully employed as matrices for the analysis of low molecular weight (LMW) peptides $(<2000 \mathrm{Da})$ including bradykinin and renin substrate tetra-decapeptide. Bovine serum albumin (BSA)-digest was also analyzed and identified through database search against Swiss-Prot by using MASCOT. The MS measurements were recorded by using dried droplet sample preparation procedures by mixing the matrix solution with analyte at a volume ratio of 1:2. Finally, LMW organic compounds $(<500 \mathrm{Da})$ were also analyzed by the synthesized matrix materials which showed better $\mathrm{S} / \mathrm{N}$ ratios and minimal background signals for low mass range in comparison to the comparable results with $\alpha$-Cyano-4-hydroxycinnamic acid (HCCA), a preferred choice for peptide analysis.
\end{abstract}

Keywords: MALDI-MS; LDI Matrix; Acylhydrazide Schiff Bases; Bis-Schiff Bases of Isatin; Schiff Bases of Isatin; Peptides

\section{Introduction}

Soft ionization by matrix-assisted laser desorption/ionization mass spectrometry (MALDI) has become very important in mass spectrometric analysis, particularly, for biological macromolecules [1]. In the MALDI processes, laser and matrix play an effective role for the ionization of analyte. MALDI utilizes both UV and IR lasers as a source of energy [2], while UV lasers are widely used in various commercially available instruments. Commonly utilized UV lasers includes $\mathrm{N}_{2}$ laser $(337 \mathrm{~nm}$ ) and frequency tripled and quadrupled Nd: YAG laser (355 $\mathrm{nm}$ and $266 \mathrm{~nm}$, respectively). Moreover, smart beam, a modified UV lasers, has recently been introduced by the Bruker which provides significant enhancement in MALDI performance [3].

Likewise, different organic compounds have been

${ }^{*}$ Corresponding author. screened for MALDI matrices. Initially, derivatives of benzoic acid, and related aromatic compounds were recognized as good MALDI matrices [4] for example, 2-(4-hydroxyphenylazo) benzoic acid, (HABA) for peptides, proteins and glycoproteins analysis [5] and 3-hydroxypicolinic acid (3-HPA) for oligonucleotides [6] were recognized as good UV-MALDI matrices. Compounds having functional groups other than carboxylic acid also have the tendency to be employed as MALDI matrices, for example, 3-aminoquinoline is a good matrix for polysaccharides and proteins [7], 2,4,6-trihydroxy acetophenone [8] and the laser dye coumarin 120 [9] has been found useful in MALDI-MS of oligonucleotides and monosulfated oligosaccharides, respectively. Fitzgerald et al. [10] introduced a number of basic matrices derived from substituted pyrimidines, pyridines, and anilines for the analysis of small proteins and nucleic acids. Recently, Y. Fukuyama et al. [11] have modified HCCA 
by attaching C-8 alkyl chain which enables it to analyze hydrophobic peptides. Similarly, S. Martic et al. [12] have prepared allylated derivatives of DHB, HCCA and caffeic acid for the efficient analysis of compounds by MALDI-MS in low molecular weight region. Overall, efforts related to the different structural modifications of existing MALDI matrices or screening of new class of compounds as MALDI matrices are limited. However, more understanding of the structural correlation with mechanistic approach of matrices is required that may results in the development of better MALDI matrices with improved performance. Moreover, appearance of a large number of interfering matrix signals in the low $\mathrm{m} / \mathrm{z}$ region is significant problem in MALDI MS analysis [13]. Different strategies have been published to analyze the analyte in the low mass region [14-27].

In this work, we have explored new classes of Schiff bases as alternate UV-LDI matrices for the analysis of low molecular weight peptides by MALDI-TOF-MS and to correlate the performance of a matrix with its chemical structure. The selection criteria of compounds was based on the structural features required for a MALDI matrix i.e. conjugated aromatic system, $\lambda_{\max }$ etc. A large number of Schiff base derivatives of acylhydrazide and isatin with necessary functionalities have been screened as potential matrices.

\section{Experimental}

\subsection{Chemicals}

Bradykinin ( $\geq 98 \%$ ), renin substrate tetra-decapeptide $(\geq$ 97\%), insulin from bovine pancreas were purchased from Sigma-Aldrich (USA). Cholic acid ( $\geq 97 \%$ ) was obtained from Wako (Japan) and chenodeoxycholic acid ( $\geq 97 \%)$ was obtained from MP Biomedical (Japan) while bovine serum albumin (BSA)-digest was purchased from Bruker Daltonics (Germany). All the solvents methanol ( $\mathrm{MeOH})$, trifluoroacetic acid (TFA), acetone $\left(\left(\mathrm{CH}_{3}\right)_{2} \mathrm{CO}\right)$, and acetonitrile (ACN) were of HPLC grade and purchased from Sigma-Aldrich (USA). Deionized water (Milli-Q) was used during the study (Millipore, USA).

\subsection{Synthesis of Matrix Materials}

Acylhydrazide Schiff bases (Class I) were synthesized from acylhydrazides which were synthesized from different esters by refluxing with hydrazine hydrate for $2 \mathrm{~h}$. Synthesized acylhydrazides were recrystallized in methanol. Acylhydrazide Schiff bases were prepared by condensing equimolar concentration of different acylhydrazide with different aromatic aldehydes and acetophenones by refluxing in ethanol for 3 to $4 \mathrm{~h}$. The crude product was further recrystallized in methanol.

Bis-Schiff bases of isatin (Class II) were synthesized from the hydrazones which prepared by refluxing a mixture of isatin $(1 \mathrm{~g})$ and hydrazine hydrate $(10 \mathrm{~mL})$. The synthesized hydrazone $(1 \mathrm{mmol})$ were refluxed with different substituted aromatic aldehydes $(1 \mathrm{mmol})$ in methanol for $3 \mathrm{~h}$. The progress of reaction was monitored by TLC. After cooling and filtration, the crystalline bisSchiff bases were collected, washed with methanol and dried to afford compounds in high yields $(>80 \%)$. Recrystallization from methanol resulted in pure crystals.

The Schiff bases of isatin (Class III) were synthesized by stirring a mixture of isatin $(1 \mathrm{mmol})$ and different substituted aromatic amines $(1 \mathrm{mmol})$ in small amount of water at room temperature for $20-30 \mathrm{~h}$. The reaction was monitored by TLC. The yellow crystalline Schiff bases were collected by filtration, washed with water and dried to get pure crystals. Detail synthetic conditions and the spectroscopic data ( ${ }^{1} \mathrm{H}$ NMR) of synthesized Schiff bases of various classes have been reported earlier [28,29].

\subsection{Preparation of Standard Solutions}

Peptide standards (Bradykinin and renin substrate tetradecapeptide) were prepared in $1 \mathrm{mM}$ concentrations in $0.1 \%$ TFA:ACN (1:1) and working standard solutions were prepared through the dilution of stock solution. BSA-digest and insulin from bovine pancreas were dissolved in $0.1 \%$ trifluoroacetic acid (TFA) in a concentration of $4 \mathrm{pmol} / \mu \mathrm{L}$ and $100 \mathrm{pmol}$, respectively. Cholic acid and chenodeoxycholic acid were prepared in methanol at the concentration of $0.1 \mu \mathrm{M}$.

\subsection{UV-Vis Absorption Measurements}

Schiff bases of acylhydrazide and bis-Schiff bases of isatin were dissolved in methanol, while Schiff bases of isatin were dissolved in acetone in a concentration range of $0.5-1.0 \mathrm{mM}$. The UV-Visible absorption maxima was recorded in the region of $200-800 \mathrm{~nm}$ by scanning against the reagent blank on a double beam UV/Visible spectrophotometer (Thermo Scientific Evolution 300, UK).

\subsection{Mass Spectrometry}

MALDI-MS measurements were carried out on Ultraflex III TOF/TOF (Bruker Daltonics, Bremen, Germany) mass spectrometer, equipped with a Smart beam laser $(\mathrm{Nd}$ : YAG, $355 \mathrm{~nm}$ ) and an electrostatic reflector. The instrument was operated in reflector mode with the ion source 1 (ISI) set to $25.00 \mathrm{kV}$, source 2 (ISI) set to $21.50 \mathrm{kV}$, a lens voltage of $9.51 \mathrm{kV}$ and laser energy was set between $50 \%-60 \%$. Flex analysis was used for the data analysis and the validation of data including the baseline subtraction. External calibration was carried out by using pep- 
tide calibration standards (Bruker Daltonics, Bremen, Germany). $0.1 \%$ TFA:ACN (1:1) was used as a solvent to prepare solutions of different synthetic matrix materials, in a concentration range of $2-5 \mu \mathrm{g} / \mu \mathrm{L}$. The solutions were sonicated for 5 minutes (Ultrasonic LC $38 \mathrm{H}$ ) and then centrifuged for 5 minutes (Centrifuge $5804 \mathrm{R} \mathrm{Ep-}$ pendorf). The supernatant was then used as matrix for the analysis. The dried droplet preparation method was used for the sample preparation by applying $1 \mu \mathrm{L}$ saturated solution of different synthetic matrix materials with analyte at a volume ratio of 1:2 to a MALDI target plate and then allowing the droplet to dry at ambient conditions which formed a homogeneous film of the matrix. The dried co-crystallized samples were then analyzed by MALDI-MS.

Recorded BSA digest spectra with a newly developed matrices were submitted to the MASCOT search engine (Matrix Science, London, UK), using UniProt/Swiss-Prot (release July 2010, Homo sapiens, 18,055 sequences) as the reference database. MASCOT search parameters were as follows: enzyme specificity trypsin, fixed modifications cysteine carbamidomethylation, variable modification methionine oxidation. The maximum number of missed cleavages was set to 3 and mass tolerance at $(0.5$ Da).

\section{Results and Discussion}

Schiff base derivatives of different class of compounds, including acylhydrazide Schiff bases (class I, nine compounds), bis-Schiff bases of isatin (class II, four compounds) and Schiff bases of isatin (class III, eighteen compounds) were screened as alternate matrices for the detection of low molecular weight peptides (Table 1).

\subsection{Spectrophotometric Analysis of Synthesized Matrices}

Wavelength maxima $\left(\lambda_{\max }\right)$ and the molar absorptivity $(\varepsilon)$ of synthetic matrix materials were determined to verify their ability to absorb the laser energy at wavelength either matching or closer to the laser wavelength $(355 \mathrm{~nm})$ employed in UV-MALDI-MS (Table 1). Strong relationship was found between the signal intensities and UV spectrophotometric properties of the matrices. This observation is attributed to the spectral data obtained by various matrices having $\lambda_{\max }$ closer to the laser and has high value of the molar absorptivity $(\varepsilon)$. However, desorption/ionization process is not exclusively dependent upon these two factors. The matrices based desorption/ionization mechanism is still not completely understood and other factors such as vacuum stability and solvent compatibility may also affect the performance of such matrices. The values of signal intensities and $\mathrm{S} / \mathrm{N}$ ratio also indicate this anomaly (Table 1).

\subsection{Screening of Schiff Base of Various Classes}

Sample preparation method and solvent selection are two important parameters which played important role in achieving better signal to noise ratio $(\mathrm{S} / \mathrm{N})$ [30,31]. All screened synthetic compounds were prepared in $0.1 \%$ TFA:ACN for screening with matrix to analyte volume ratio of 1:2 for the detection of low molecular weight peptides $(<2000 \mathrm{Da})$, bradykinin and renin substrate tetra-decapeptide.

Nine compounds of class I ( 1 - 9) possessing $\lambda_{\max }$ between 304 - $339 \mathrm{~nm}$ were screened and found comparable to the existing MALDI matrix, HCCA in terms of intensity for the detection of peptides. Compounds 1, 2, 5 and 7 showed very high signal intensity $\left(>1 \times 10^{5}\right)$ for peptides (Table 1). Four compounds of class II (10 - 13) possessing $\lambda_{\text {max }}$ between $331-346 \mathrm{~nm}$ were screened as LDI matrix. All of them showed high intensity $\left(>1 \times 10^{4}\right)$ of analyzed samples and were found suitable to be used as MALDI matrices for the analysis of low molecular weight peptides (Table 1). Similarly, eighteen compounds of class III (14 - 31), having $\lambda_{\max }$ between $326-$ $416 \mathrm{~nm}$, showed good signal intensity $\left(>1 \times 10^{4}\right)$ of both peptides (Table 1). Overall, newly developed matrices produced excellent signal intensities of analytes with high reproducibility. Compounds 5, 10 and 31 when employed to analyze bradykinin peptide produced very high intensities with a standard deviation of \pm 0.15 (Figure 1), while the renin peptide analyzed with compounds 1,10 and 31 afford similar results with a standard deviation of \pm 0.10 (Figure 2). However, almost no background signals were observed in the low mass region from these new matrices, hence, found suitable for the analysis of small molecules.

In all classes, a common chromophore was Schiff base while different aromatic substituents were attached to ty each class which enhanced both $n-\pi^{*}$ and $\pi-\pi^{*}$ transitions through electron lone pair on hetro atom and conjugated double bond system which produced the hyperchromic and bathochromic effects thus resulted in longer $\lambda_{\max }$ therefore, requires less energy for the excitation. This factor is directly related to the amount of laser power required to get a good intensity signal from a sweet spot on MALDI target.

Moreover, among the all screened compounds, acylhydrazide Schiff bases (class I) showed excellent signal intensities. Therefore, compounds from class I were selected for further studies. BSA-digest sample was analyzed by using compounds of class I $(1-7)$ to evaluate their ability to analyze peptides in complex biological samples. The spectrum showed promising signals of peptides (Figure 3) and the resulting mass spectrum were subjected to the database search against Swiss-Prot, using MASCOT for the identification. The sequence 
Table 1. The $\lambda_{\max }$ and molar absorptivities of different classes of compounds.

\begin{tabular}{|c|c|c|c|c|c|}
\hline$\#$ & Matrix Classes & Structure & $\lambda_{\max }(\mathrm{nm})$ & $\varepsilon^{\mathrm{a}}$ & $\log \varepsilon$ \\
\hline & Class (I) Acylhydrazide Schiff bases & & & & \\
\hline 1. & $\begin{array}{l}\text { 2-Hydroxy- } N \text { '-[(2-methyl-1H-indol-3-yl) } \\
\text { methylene }] \text { benzohydrazide }\end{array}$ & & 315 & 16,274 & 4.2 \\
\hline 2. & $\begin{array}{c}\text { 4-Methyl- } N \text { '-[(2-methyl- } 1 H \text {-indol-3-yl }) \\
\text { methylene]benzohydrazide }\end{array}$ & & 334 & 13,514 & 4.1 \\
\hline 3. & $\begin{array}{c}\text { 4-Bromo- } N^{\prime}-[(2-\text {-methyl- } 1 H \text {-indol-3-yl }) \\
\text { methylene }] \text { benzohydrazide }\end{array}$ & & 338 & 20,900 & 4.3 \\
\hline 4 & $\begin{array}{c}\text { N'-[(4-Hydroxyphenyl)methylene]nonano } \\
\text { Hydrazide }\end{array}$ & & 334 & 13,368 & 4.1 \\
\hline 5. & $\begin{array}{l}\text { 4-Chloro- } N^{\prime}-[(2-\text { methyl- } 1 H \text {-indol-3yl }) \\
\text { methylene]benzohydrazide }\end{array}$ & & 339 & 20,211 & 4.3 \\
\hline 6. & $\begin{array}{l}\text { 4-Bromo- } N \text { '-[(4-hydroxyphenyl) } \\
\text { methylene]benzohydrazide }\end{array}$ & & 334 & 17,228 & 4.2 \\
\hline 7. & $\begin{array}{l}\left.N^{\prime} \text {-[(4-Hydroxyphenyl)methylene }\right]-2 \text {-thiophene } \\
\text { carbohydrazide }\end{array}$ & & 337 & 16,358 & 4.2 \\
\hline 8. & $\begin{array}{l}\left.N^{\prime} \text {-[(4-Chlorophenyl)methylene }\right]-2-\text { thiophene } \\
\text { carbohydrazide }\end{array}$ & & 311 & 12,472 & 4.1 \\
\hline 9. & $\begin{array}{l}\text { 4-Fluoro- } N^{\prime} \text {-[(2-hydroxy-3-methoxyphenyl) } \\
\text { methylene] benzohydrazide }\end{array}$ & & 304 & 18,188 & 4.3 \\
\hline & Class (II) Bis-Shiff bases of isatin & & & & \\
\hline
\end{tabular}




\section{Continued}

10. 2-Hydroxybenzaldehyde-N-(2-oxo-1, 2-dihydro-3H- indol-3-ylidene) hydrazone<smiles>[R]#Cc1ccccc1O</smiles>

11.

4-Fluorobenzaldehyde-N-(2-oxo-1, 2-dihydro-3H-indol-3-ylidene) hydrazone<smiles></smiles>

12.

2-Fluorobenzaldehyde-N-(2-oxo-1, 2-dihydro-3H-indol-3-ylidene) hydrazone<smiles>[R]#Cc1[12cH][13cH][14cH][14c](F)[14cH]1</smiles>

13. 2-Hydroxy-3-methoxy benzaldehyde-N(2-oxo-1,2-dihydro-3H-indol-3-ylidene) hydrazone<smiles>[R]Cc1cccc(OC)c1O</smiles>

\section{Class (III) Schiff base of isatin}

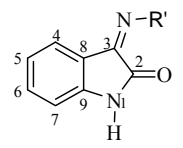

14. 3-(Phenylimino)-1 $H$-indol-2-one<smiles>[R]#[X]c1ccccc1</smiles>

15. 3-[(2-Chlorophenyl)imino]-1H-indol-2-one<smiles>[R]#Cc1ccccc1Cl</smiles>

16. 3-[(3-Chlorophenyl)imino]-1H-indol-2-one<smiles>[R]#C[14c]1[14cH][14cH][14cH][14c](Cl)[14cH]1</smiles>

17. 3-[(4-Chlorophenyl)imino]-1H-indol-2-one<smiles></smiles>

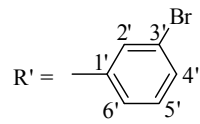

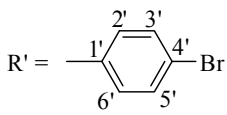
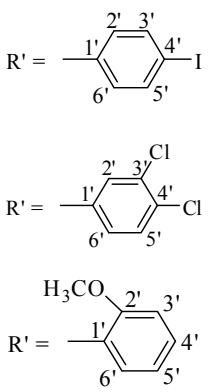

24. 


\section{Continued}

25. 3-[(2-Methylphenyl)imino]-1H-indol-2-one<smiles>[R]C1=CC=[C+]C=C1C</smiles>

26.

3-[(3-Methylphenyl)imino]-1 $H$-indol-2-one<smiles>[R]c1cc[c-]cc1C</smiles>

27.

3-[(4-Methylphenyl)imino]-1 $H$-indol-2-one<smiles>[R]Cc1ccc(C)cc1</smiles><smiles>Cc1ccccc1C</smiles>

29. 3-[(2,5-Dimethylphenyl)imino $]-1 H$-indol-2-one<smiles>[R]c1cc(C)ccc1C</smiles>

31.

3-[(3-Methoxy-4-methylphenyl)<smiles>[R]Cc1ccc(C)c(OC)c1</smiles>

$\mathrm{a}=\left(\mathrm{L} \mathrm{Mol}^{-1} \cdot \mathrm{cm}^{-1}\right)$

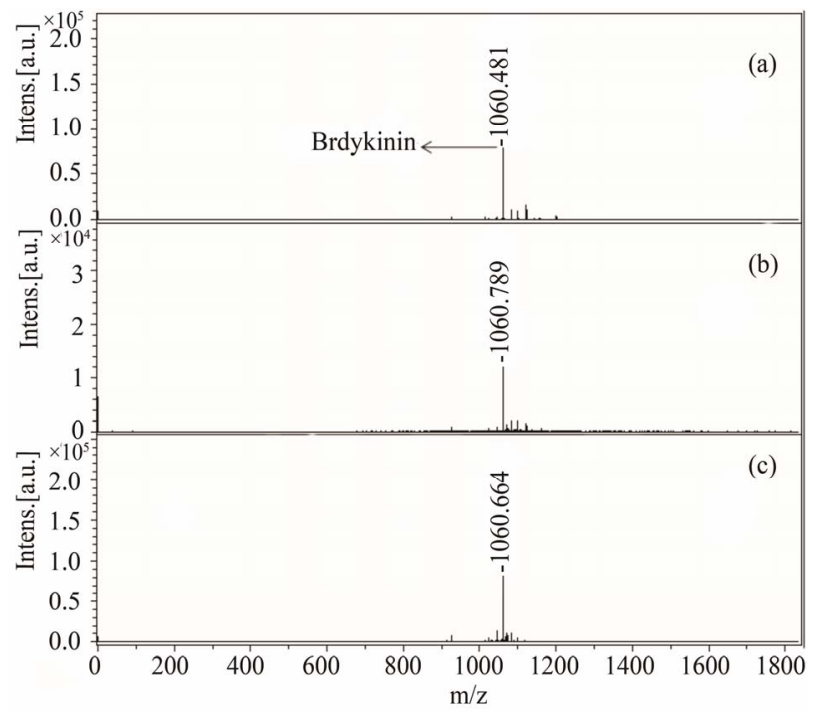

Figure 1. MALDI-TOF-MS spectra of a peptide bradykinin (50 pM) by applying different matrices (a) 5, (b) 10, and (c) 31 . All bradykinin spectra were recorded in reflector mode by averaging 600 laser shots.

coverage of BSA using compound 1 was $44 \%$ (with average MASCOT score 105) and found to be very close with HCCA which gave 61\% sequence coverage (with

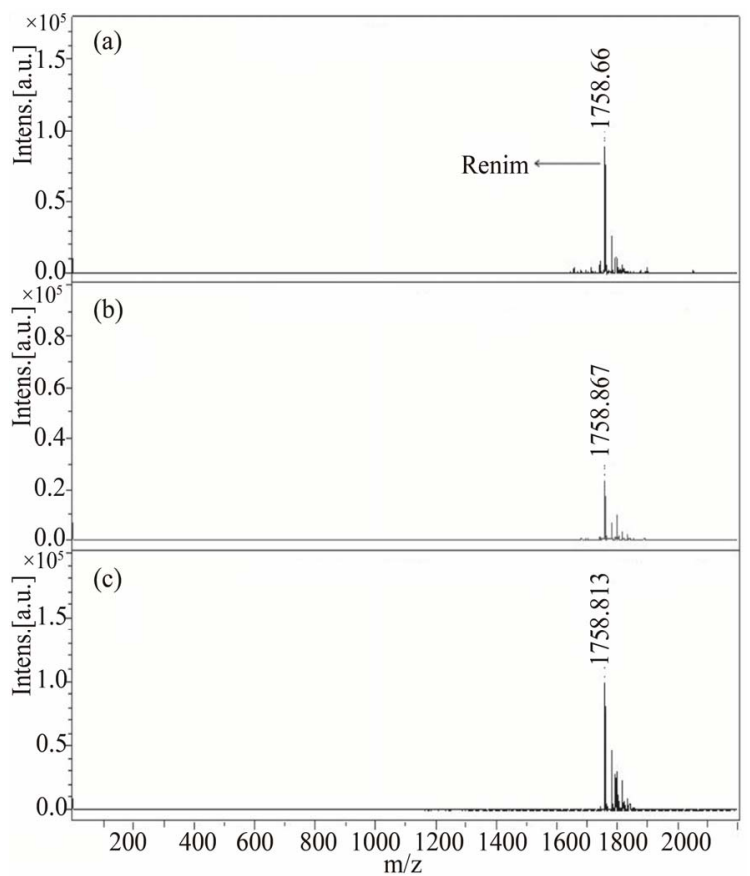

Figure 2. MALDI-TOF-MS spectra of a peptide rennin (50 pM) by applying different matrices (a) 1, (b) 10, and (c) 31 . All rennin spectra were recorded in reflector mode by averaging 600 laser shots. 


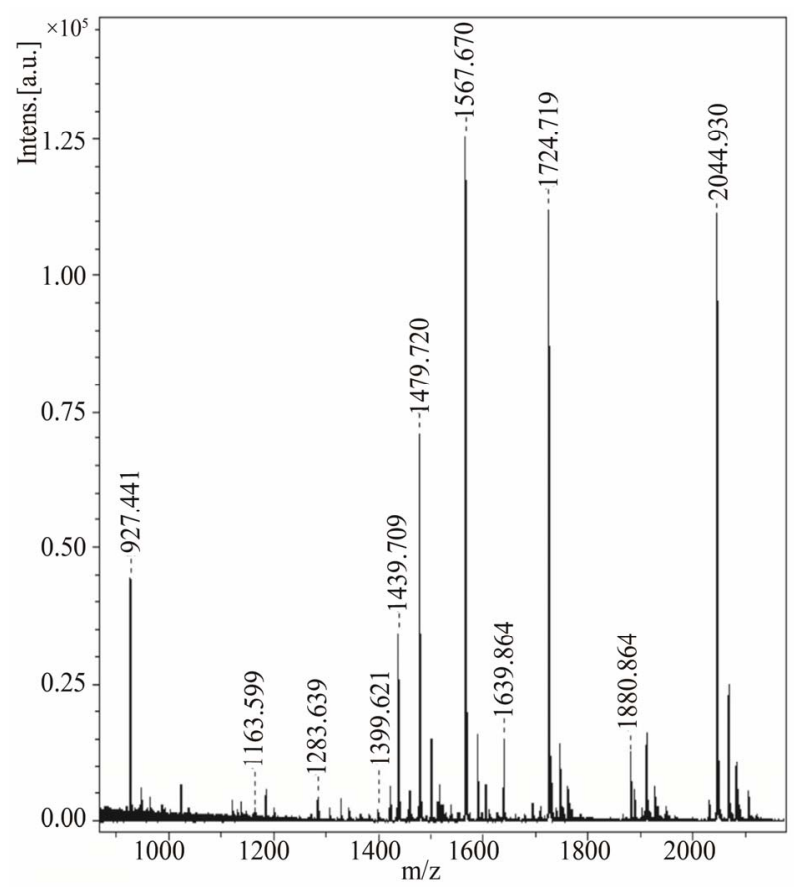

Figure 3. MALDI-TOF-MS spectra of BSA-digest with compound 3 as a matrix. BSA-digest $(4 \mathrm{pmol} / \mu \mathrm{L}$ on target) spectra were recorded in reflector mode by averaging 600 laser shots.

average MASCOT score of 81 ), proving the ability to analyze peptides in complex biological samples (Table 2). Moreover, a protein, insulin (5733.492 Da) was also analyzed with compounds 1,3 and 7 as an LDI matrix to observe the performance of these matrices in high mass region. These showed comparable results with HCCA (Figure 4) therefore, such compounds can also be employed to analyze proteins.

In order to evaluate the performance of new matrices in analyzing small molecules and to observe the background signals generated in low mass region, two low molecular weight compounds, cholic acid (408.57 Da) and chenodeoxycholic acid (392.57 Da) were analyzed. Cholic acid $(0.1 \mu \mathrm{M})$ solution was analyzed with three different matrices (compounds 3, 13 and 31) showing excellent reproducibility with a standard deviation of only \pm 0.003 , (Figure 5). Compound 3 (class I) was also used to analyze chenodeoxycholic acid which appeared at $m / z 393.85$ as $[\mathrm{M}+\mathrm{H}]^{+}$while its potassium adduct $[\mathrm{M}+\mathrm{K}]^{+}$appeared at $\mathrm{m} / \mathrm{z} 431.13$ (Figure 6). There was large number of interfering signals observed in lower mass range when analyzed with HCCA making it difficult to identify the chenodeoxycholic acid. Whereas the spectra of cholic acid and chenodeoxycholic acid recorded with the new matrices were very clean and nominal interfering signals were detected showing the ability of these new matrices to be used in the identification of metabolites.
Table 2. Data-base search results of BSA-digest, analyzed with various matrices.

\begin{tabular}{cccc}
\hline Compounds & $\begin{array}{c}\text { Average } \\
\text { MASCOT } \\
\text { Score }\end{array}$ & $\begin{array}{c}\text { Average } \\
\text { number of } \\
\text { Peptides }\end{array}$ & $\begin{array}{c}\text { \% Sequence } \\
\text { coverage }\end{array}$ \\
\hline $\mathbf{1}$ & 105 & 23 & 44 \\
$\mathbf{2}$ & 106 & 15 & 30 \\
$\mathbf{3}$ & 89 & 12 & 23 \\
$\mathbf{5}$ & 108 & 11 & 22 \\
$\mathbf{6}$ & 93 & 19 & 34 \\
$\mathbf{7}$ & 69 & 6 & 12 \\
HCCA & 93 & 10 & 20 \\
\hline
\end{tabular}

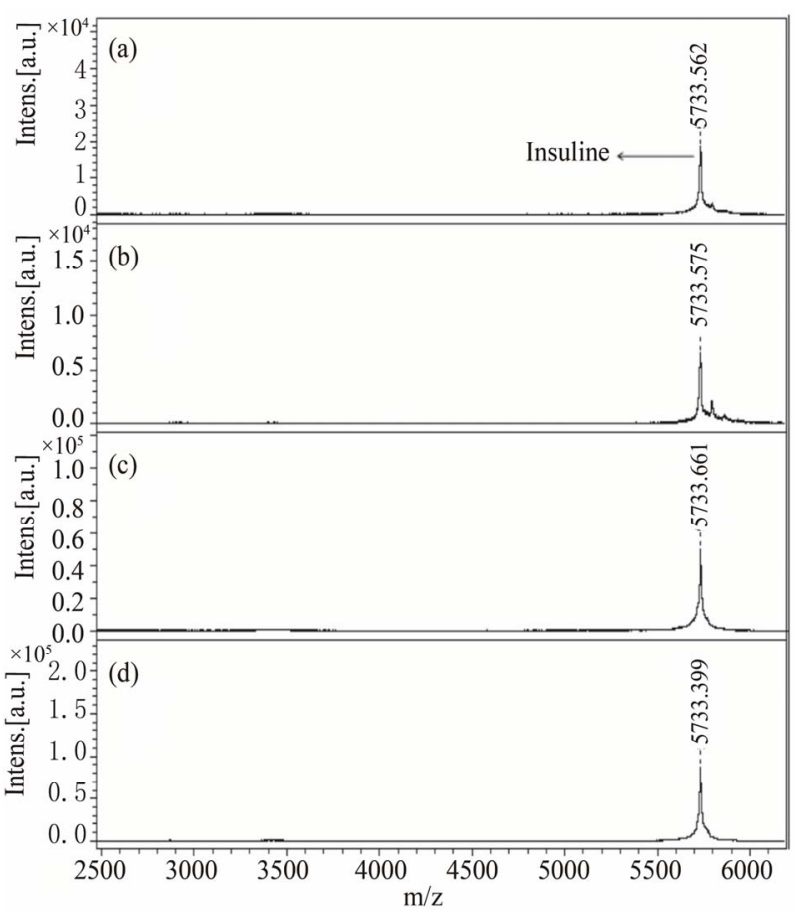

Figure 4. MALDI-TOF-MS spectra of a insulin (protein) by applying different matrices (a) 1, (b) 3 and (c) 7 and (d) HCCA. All insulin were recorded in reflector mode by averaging 600 laser shots.

The thickness of the co-crystallized analyte-matrix on MALDI plate is quite small, which offers an additional advantage of the newly developed matrices, as thicker films (especially observed in suspension-based matrix systems) cause shifting of the masses during MALDI experiments. Interestingly no mass shift was observed during the exact mass measurement in our experiments and the observed masses were found identical to their theoretical masses. Moreover, the newly synthetic matrices showed homogeneous co-crystallization with the 


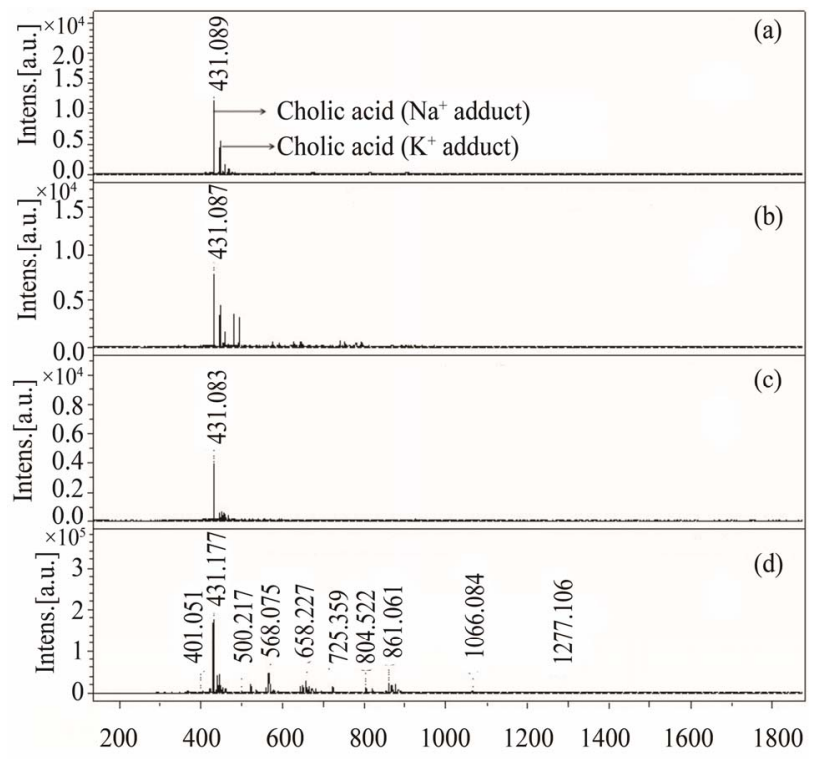

Figure 5. MALDI-TOF-MS spectra of cholic acid (0.1 $\mu \mathrm{M})$ by applying different matrices (a) 3, (b) 13 (c) 31 and (d) HCCA. All cholic acid spectra were recorded in reflector mode by averaging 600 laser shots.

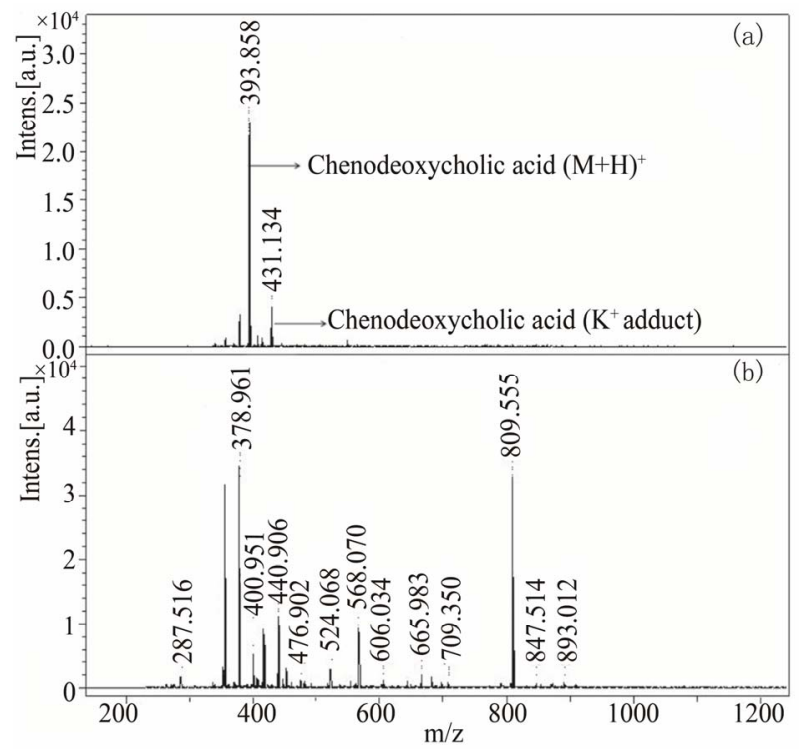

Figure 6. MALDI-TOF-MS spectra of chenodeoxycholic acid $(0.1 \mu \mathrm{M})$ with compounds used as a matrix (a) 3 and (b) HCCA. All chenodeoxycholic acid spectra were recorded in reflector mode by averaging 600 laser shots.

analyte which is important to achieve the best spectral parameters (resolution, intensity and $\mathrm{S} / \mathrm{N}$ ratio) especially when MALDI-MS spectra are recorded in an automatic mode.

\section{Conclusion}

We have reported here thirty one synthesized alternate matrices for the desorption and ionization of intact small peptides and compounds. Large number of Schiff bases of acylhydrazide, Schiff base and bis-Schiff bases of isatin with necessary functionalities have been screened. These LDI matrices have an ability to ionize the analyte molecules and act as energy absorbing materials at the employed laser wavelength with minimum background signals. As alternate LDI matrices, a number of conjugated aromatic systems in their structures ensure the laser energy transformations to the analytes. Furthermore, this approach lead to the development of structure-property relationship models, which in turn, could lead to a better understanding of the MALDI mechanism and the development and discovery of better matrices in future.

\section{REFERENCES}

[1] J. Gross and K. Strupat, "Matrix-Assisted Laser Desorption/Ionization Mass Spectrometry Applied to Biological Macromolecules," Trends in Analytical Chemistry, Vol. 17, No. 8-9, 1998, pp. 470-484. doi:10.1016/S0165-9936(98)00060-0

[2] D. J. Rousell, S. M. Dutta, M. W. Little and K. K. Murray, "Matrix-Free Infrared Soft Laser Desorption/Ionization," Journal of Mass Spectrometry, Vol. 39, No. 10, 2004, pp. 1182-1189. doi:10.1002/jms.706

[3] A. Holle, A. Haase, M. Kayser and J. Hohndorf, "Optimizing UV Laser Focus Profiles for Improved MALDI Performance," Journal of Mass Spectrometry, Vol. 41, No. 6, 2006, pp. 705-716.

[4] J. Krause, M. Stoeckli and U. P. Schlunegger, "Studies on the Selection of New Matrices for Ultraviolet Matrix-Assisted Laser Desorption Ionization Time-of-Flight Mass Spectrometry," Rapid Communication in Mass Spectrometry, Vol. 10, No. 15, 1996, pp. 1927-1933.

doi:10.1002/(SICI)1097-0231(199612)10:15<1927::AID$\underline{\mathrm{RCM} 709>3.0 . \mathrm{CO} ; 2-\mathrm{V}}$

[5] P. Juhasz, P. Costello and K. Biemann, "Matrix-Assisted Laser Desorption Ionization Mass Spectrometry with 2(4-Hydroxyphenylazo) Benzoic Acid Matrix," Journal of the American Society for Mass Spectrometry, Vol. 4, No. 5, 1993, pp. 399-409. doi:10.1016/1044-0305(93)85005-I

[6] K. J. Wu, A. Steding and C. H. Becker, "Matrix-Assisted Laser Desorption Time-of-Flight Mass Spectrometry of Oligonucleotides Using 3-Hydroxypicolinic Acid as an Ultraviolet-Sensitive Matrix," Rapid Communication in Mass Spectrometry, Vol. 7, No. 2, 1993, pp. 142-146. doi:10.1002/rcm.1290070206

[7] J. O. Metzger, R. Woisch, W. Tuszynski and R. Angermann, "New Type of Matrix for Matrix-Assisted Laser Desorption Mass Spectrometry of Polysaccharides and Proteins," Fresenius Journal of Analytical Chemistry, Vol. 349, No. 6, 1994, pp. 473-474. doi:10.1007/BF00322937

[8] U. Pieles, W Zürcher, M Schär and H. Moser, "Matrix-Assisted Laser Desorption Ionization Time-of-Flight Mass Spectrometry: A Powerful Tool for the Mass and Sequence Analysis of Natural and Modified Oligonucleo- 
tides," Nucleic Acids Research, Vol. 21, No. 14, pp. 31913196.

[9] Y. Dai, R. M. Whittal, C. A. Bridges, Y. Isogai, O. Hindsgaul and L. Li, "Matrix-Assisted Laser Desorption Ionization Mass Spectrometry for the Analysis of Monosulfated Oligosaccharides," Carbohydrate Research, Vol. 304, No. 1, 1997, pp. 1-9. doi:10.1016/S0008-6215(97)00195-X

[10] M. C. Fitzgerald, G. R. Parr and L. M. Smith, "Basic Matrices for the Matrix-Assisted Laser Desorption/Ionization Mass Spectrometry of Proteins and Oligonucleotides," Analytical Chemistry, Vol. 65, No. 22, 1993, pp. 3204-3211. doi:10.1021/ac00070a007

[11] Y. Fukuyama, R. Tanimura, K. Maeda, M. Watanabe, S. Kawabata, S. Iwamoto, S. Izumi and K. Tanaka, "Alkylated Dihydroxybenzoic Acid as a MALDI Matrix Additive for Hydrophobic Peptide Analysis," Analytical Chemistry, Vol. 84, No. 9, 2012, pp. 4237-4243. doi:10.1021/ac300540r

[12] S. Martic, J. D. Brennan, M. A. Brook, S. Ackloo and N. Nagy, "Towards the Development of a Covalently Tethered MALDI System-A Study of Allyl-Modified MALDI Matrixes," Canadian Journal of Chemistry, Vol. 85, No. 1, 2007, pp. 66-76. doi:10.1139/v06-185

[13] Z. Guo, Q. Zhang, H. Zou, B. Guo and J. Ni, "A Method for the Analysis of Low-Mass Molecules by MALDITOF Mass Spectrometry," Analytical Chemistry, Vol. 74, No. 7, 2002, pp. 1637-1641. doi:10.1021/ac010979m

[14] G. McCombie and R. Knochenmuss, "Small-Molecule MALDI using the Matrix Suppression Effect to Reduce or Eliminate Matrix Background Interferences," Analytical Chemistry, Vol. 76, No. 17, 2004, pp. 4990-4997. doi:10.1021/ac049581r

[15] F. O. Ayorinde, P. Hambright, T. N. Porter and Q. L. Keith, "Use of Meso-Tetrakis (Pentafluorophenyl) Porphyrin as a Matrix for Low Molecular Weight Alkyl Phenol Ethoxylates in Laser Desorption/Ionization Time-of-Flight Mass Spectrometry," Rapid Communication in Mass Spectrometry, Vol. 13, No. 24, 1999, pp. 2474-2479. doi:10.1002/(SICI)1097-0231(19991230)13:24<2474::AI D-RCM814>3.0.CO;2-0

[16] A. Tholey and E. Heinzle, "Ionic (Liquid) Matrices for Matrix-Assisted Laser Desorption/Ionization Mass Spectrometry-Applications and Perspectives," Analytical and Bioanalytical Chemistry, Vol. 386, No. 1, 2006, pp. 24-37. doi:10.1007/s00216-006-0600-5

[17] D. W. Armstrong, L. Zhang, L. He and M. L. Gross, "Ionic Liquids as Matrixes for Matrix-Assisted Laser Desorption/Ionization Mass Spectrometry," Analytical Chemistry, Vol. 73, No. 15, 2001, pp. 3679-3686. doi:10.1021/ac010259f

[18] M. Najam-ul-Haq, M. Rainer, C. W. Huck, P. Hausberger, H. Kraushaar and G. K. Bonn, "Nanostructured Diamond-Like Carbon on Digital Versatile Disc as a Matrix-Free Target for Laser Desorption/Ionization Mass Spectrometry," Analytical Chemistry, Vol. 80, No. 19, 2008, pp. 7467-7472.

[19] J. Wei, J. M. Buriak and G. Siuzdak, "Desorption-Ionizationmass Spectrometry on Porous Silicon," Letters to
Nature, Vol. 399, No. 77, 1999, pp. 243-246. doi: $10.1038 / 20400$

[20] S. Zhang, Y. Chen, J. A. Liu, S. X. Xiong, G. H. Wang, J. Chen and G. Q. Yang, "New Matrix of MALDI-TOF MS for Analysis of Small Molecules," Chinese Chemical Letters, Vol. 20, No. 12, 2009, pp. 1495-1497. doi:10.1016/j.cclet.2009.06.031

[21] T. Kinumi, T. Saisu, M. Takayama and H. Niwa, "Matrix-Assisted Laser Desorption/Ionization Time-of-Flight Mass Spectrometry Using an Inorganic Particle Matrix for Small Molecule Analysis," Journal of Mass Spectrometry, Vol. 35, No. 3, 2000, pp. 417-422. doi:10.1002/(SICI)1096-9888(200003)35:3<417::AID-J MS952>3.0.CO;2-\#

[22] S. Ren, L. Zhang, Z. Cheng and Y. Guo, "Immobilized Carbon Nanotubes as Matrix for MALDI-TOF-MS Analysis: Applications to Neutral Small Carbohydrates," Journal of the American Society for Mass Spectrometry, Vol. 16, No. 3, 2005, pp. 333-339. doi:10.1016/j.jasms.2004.11.017

[23] X. Dong, J. Cheng, J. Li and Y. Wang, "Graphene as a Novel Matrix for the Analysis of Small Molecules by MALDI-TOF MS," Analytical Chemistry, Vol. 82, No. 14, 2010, pp. 6208-6214. doi:10.1021/ac101022m

[24] H. Kim, J. Lee, S. Park, H. W. Ro, D. Y. Yoo and D. Y. Yoon, "Observation of Low Molecular Weight Poly (Methylsilsesquioxane)s by Graphite Plate Laser Desorption/ Ionization Time-of-Flight Mass Spectrometry," Analytical Chemistry, Vol. 72, No. 22, 2000, pp. 5673-5678. doi:10.1021/ac0003899

[25] M. J. Dale, R. Knochenmuss and R. Zenobi, "Graphite/ Liquid Mixed Matrices for Laser Desorption/Ionization Mass Spectrometry," Analytical Chemistry, Vol. 68, No. 19, 1996, pp. 3321-3329. doi:10.1021/ac960558i

[26] C. Black, C. Poile, J. Langley and J. Herniman, "The Use of Pencil Lead as a Matrix and Calibrant for Matrix-Assisted Laser Desorption/Ionization," Rapid Communication in Mass Spectrometry, Vol. 20, No. 7, 2006, pp. 1053-1060. doi:10.1002/rcm.2408

[27] G. J. Langley, J. M. Herniman and M. S. Townell, “2B Or Not 2B, That is the Question: Further Investigations into the Use of Pencil as a Matrix for Matrix-Assisted Laser Desorption/Ionization," Rapid Communication in Mass Spectrometry, Vol. 21, No. 2, 2007, pp. 180-190. doi: $10.1002 / \mathrm{rcm} .2827$

[28] K. M. Khan, M. Khan, M. Ali, M. Taha, S. Rasheed, S. Perveen and M. I. Choudhary, "Synthesis of Bis-Schiff Bases of Isatins and their Antiglycation Activity," Bioorganic \& Medicinal Chemistry, Vol. 7, No. 22, 2009, pp. 7795-7801. doi:10.1016/j.bmc.2009.09.028

[29] K. M. Khan, U. R. Mughal, Samreen, S. Perveen and M. I. Choudhary, "Schiff Bases of Isatin: Potential Anti-Leishmanial Agents," Letters in Drug Design \& Discovery, Vol. 5, No. 4, 2008, pp. 243-249. doi:10.2174/157018008784619915

[30] M. W. F. Neilen, "MALDI Time-of-Flight Mass Spectrometry of Synthetic Polymers." Mass Spectrometry Reviews, Vol. 18, No. 5, 1999, pp. 309-344. doi:10.1002/(SICI)1098-2787(1999)18:5<309::AID-MAS 


\section{2>3.0.CO;2-L}

[31] S. F. Macha, P. A. Limbach and P. J. Savickas, “Application of Nonpolar Matrices for the Analysis of Low Molecular Weight Nonpolar Synthetic Polymers by Matrix-
Assisted Laser Desorption/Ionization Time-of-Flight Mass Spectrometry," Journal of the American Society for Mass Spectrometry, Vol. 11, No. 8, 2000, pp. 731-773. doi:10.1016/S1044-0305(00)00137-9 


\section{Appendix}

Table A1. Signal intensity and S/N ratio of synthetic matrix material with low molecular weight analytes.

\begin{tabular}{|c|c|c|c|c|}
\hline \multirow{2}{*}{ Compounds } & \multicolumn{2}{|c|}{ Bradykinin } & \multicolumn{2}{|c|}{ Renin substrate tetra-decapeptide } \\
\hline & $\mathbf{S} / \mathbf{N}$ & Sig. Int. & $\mathbf{S} / \mathbf{N}$ & Sig. Int. \\
\hline 1 & 1243 & 303,774 & 378 & 89,505 \\
\hline 2 & 186 & 122,638 & 760 & 70,670 \\
\hline 3 & 1078 & 59,705 & 702 & 55,347 \\
\hline 4 & 513 & 79,804 & 191 & 34,052 \\
\hline 5 & 1114 & 97,047 & 7151 & 82,709 \\
\hline 6 & 246 & 73,297 & 192 & 34,052 \\
\hline 7 & 892 & $1,268,674$ & 1417 & 74,896 \\
\hline 8 & 160 & 1687 & 236 & 10,335 \\
\hline 9 & 951 & 58,606 & 834 & 95,126 \\
\hline 10 & 352 & 12,917 & 643 & 88,445 \\
\hline 11 & 992 & 126,386 & 250 & 59,958 \\
\hline 12 & 706 & 83,512 & 648 & 53,400 \\
\hline 13 & 344 & 69,710 & 356 & 60,418 \\
\hline 14 & 523 & 62,378 & 423 & 23,762 \\
\hline 15 & 204 & 40,104 & 236 & 41,150 \\
\hline 16 & 292 & 73,000 & 362 & 38,828 \\
\hline 17 & 497 & 77,183 & 426 & 33,273 \\
\hline 18 & 1835 & 153,067 & 781 & 150,047 \\
\hline 19 & 386 & 86,938 & 276 & 45,939 \\
\hline 20 & 699 & 106,798 & 330 & 98,533 \\
\hline 21 & 502 & 105,059 & 308 & 98,153 \\
\hline 22 & 288 & 45,002 & 434 & 47,010 \\
\hline 23 & 150 & 51,728 & 318 & 75,890 \\
\hline 24 & 538 & 87,681 & 451 & 105,636 \\
\hline 25 & 444 & 26,336 & 1015 & 110,685 \\
\hline 26 & 509 & 86,173 & 681 & 79,172 \\
\hline 27 & 736 & 58,769 & 297 & 59,142 \\
\hline 28 & 330 & 56,341 & 800 & 21,265 \\
\hline 29 & 347 & 64,819 & 375 & 131,250 \\
\hline 30 & 214 & 19,307 & 265 & 18,867 \\
\hline 31 & 171 & 62,204 & 357 & 102,072 \\
\hline HCCA & 832 & 86,824 & 378 & 89,505 \\
\hline
\end{tabular}

